\title{
The drying and rehydration process of chayote (Sechium edule)
}

\author{
Álvarez-Morales, A. a*; Luna-Solano, G. ${ }^{\text {b; }}$ Ramírez-Martínez, A $^{\text {a }}$ \\ ${ }^{a}$ Department of Food Engineering. Tecnológico Nacional de México-Instituto Tecnológico Superior \\ de Huatusco, Huatusco, México. \\ b Department of Chemistry. Tecnológico Nacional de México-Instituto Tecnológico de Orizaba, \\ Orizaba, México.
}

*E-mail of the corresponding author: alejandrarm@itshuatusco.edu.mx

\begin{abstract}
Chayote (Sechium edule) is a fruit that is said to be a nutritional and have healing properties. $90 \%$ of its weight is made up of water which makes this fruit highly perishable. Convective drying is an excellent option to reduce the loss of this product as well as prolong its shelf life. Thus, the main objective of this work was to assess the physicochemical characteristics of different chayote samples (slices, cubes and strips) during its drying and rehydration process. Results suggest that cubes represent an alternative for commercial use as an additive in foodstuffs due to their size.
\end{abstract}

Keywords: chayote; convective drying; rehydration process; physiochemical properties. 


\section{Introduction}

The chayote (Sechium edule) is native to Mesoamerica where the greatest genetic diversity is found, however, it can also be found in other parts of the world. Mexico is one of the leading producers of this fruit which losses up to $25 \%$ of the harvest due to bad practices during the postharvest, particularly during the storage and refrigeration of the product as estimated by local producers. These bad practices lead to physical damages that generate darkening in the pericarp, formation of depressions, incomplete maturation, susceptibility to microbial attack, formation of shoots and weight loss [1].

Resarchers have studied methods for the preservation of the fruit due to its good nutritional and healing properties as well as for its accessibility to low-income groups [2] [3] [4] [5]. Chayote has a low content of lipids, proteins and calories, and is an important source of minerals, aminoacids and vitamins. At the same time, this fruit is highly perishable because about $95 \%$ of its fresh weight is water [6]. The reported properties of chayote include diuretic (leaves and seeds), as well as cardiovascular and anti-inflammatory properties (leaves and flesh). Also, the consumption of chayote was associated with the reduction of the retention of urine and burning when urinating when kidney stones are dissolved [7].

The drying process allows prolonging the shelf life of foods with high moisture content. Convective drying may particularly constitute a good option for the conservation of chayote due to the ease of the operation of convective driers as well as the relative simplicity in the handling of the samples to be treated. On the other hand, the analysis of the rehydration of dried food is necessary since it allows to evaluate indirectly the damage that occurred in the food due to the drying process. Moreover, it is fundamental to evaluate the physicochemical properties of rehydrated foods to ensure the conservation of their flavor and sensorial properties. To date, there are few studies where the physiochemical characteristics of the chayote during its drying and rehydration process are evaluated. On that basis, the aim of this work was to, determine the drying characteristics of samples of chayote cut in three different geometric shapes (cubes, slices and strips) dried in a convective dryer at temperature of $60^{\circ} \mathrm{C}$; to study the drying process parameters on the physical and chemical properties of this fruit (water, moisture and color activity); and to study the rehydration process of the samples obtained in the drying process.

\section{Materials and Methods}

\subsection{Selection and characterization of the raw material}

Export-quality chayote samples (Sechium edule v. virens levis) from the city of Campo Grande located in the municipality of Ixtacxoquitlan, Veracruz were used in the present study. Chayote samples fruits were completely smooth and without spines. They weighted 
between 200-300 g, had an average moisture content of $92.8 \%$ and water activity $\left(a_{w}\right)$ of 0.994 , in average.

After the selection of the samples, they were washed and cut with a manual cutter in three different geometric shapes: slices $(5 \mathrm{~cm}$ diameter and $0.5 \mathrm{~cm}$ thickness), cubes $(1 \mathrm{~cm}$ length); and strips ( $7 \mathrm{~cm}$ height, $1 \mathrm{~cm}$ length and $0.5 \mathrm{~cm}$ thickness).

\subsection{Drying process}

Tests were conducted in a pilot plant scale vertical tray dryer (MOD-SEM-2 Polinox, MX). Drying tests were carried out at a temperature of $60^{\circ} \mathrm{C}$ and the air velocity was imposed at $1.2 \mathrm{~m} / \mathrm{s}$. In each test, the drying kinetics were evaluated by recording the moisture content change as function of time. During the drying process, samples were taken to analyze the main physical-chemical parameters ( $a_{w}$, moisture content and color) every 15 minutes during the first hour, 30 minutes in the following hour, and finally every 60 min until the water activity of samples reached 0.6. Tests were conducted in duplicate.

Drying kinetic data was adjusted to three common models employed in the drying process to model data: Page model, Newton model and Henderson-Pabis model (Table 1) where $M_{R}$ corresponds to the adimensional moisture content and $\mathrm{k}, \mathrm{k}_{1}, \mathrm{k}_{2}, \mathrm{k}_{3}$, a and $\mathrm{n}$ are model paramters. For this purpose, the moisture moisture content $\left(M_{R}\right)$ was expressed as the moisture ratio $\left(M_{R}\right)$ by means of eq. (1):

$$
M_{R}=\frac{X}{X_{0}}
$$

Where $X$ corresponds to the moisture content at any time in $\mathrm{g}$ water/g of dry solid and $X_{0}$ is the initial moisture content in $\mathrm{g}$ water/g of dry solid. The goodness-of-fit of the data to the proposed models was evaluated by means of the $\mathrm{R}^{2}$ parameter.

\subsubsection{Physicochemical characterization of the chayote}

Water activity was determined using the AquaLab equipment (AquaLab Series 3 TE model, USA) in conditions of $25 \pm 1^{\circ} \mathrm{C}$. Moisture content (X) was determined by means of an Infrared moisure analyzer (Sartorius MA35, USA). In order to obtain more realisitc moisture content values, the moisture analyzer was warmed up for 30 minutes prior the determination of the moisture content. After this, the samples used for the determination of $\mathrm{X}(1 \mathrm{~g})$ were returned to the dryer chamber where they were previously taken.. The color was determined by using a MiniScan XE plus colorimeter (HunterLab, USA). The color measurement was carried out by placing the sample inside the equipment, thus, acquiring the color parameters corresponding to the luminosity: $\mathrm{L} *$, and chromaticity: $\mathrm{a} *$ and $\mathrm{b} *$. The color data was captured in a computer integrated to the colorimeter and processed by a software application (Universal software 4.10, USA) to obtain the total difference of color $(\Delta \mathrm{E})$. Tests were conducted in duplicate. 


\subsection{Rehydration of convective dried chayote samples}

The adsorption capacity of the samples was determined by weighing $0.5 \mathrm{~g}$ of the dried chayote samples on an electronic analytical balance (Santorius TE14S, USA). Then, the samples were submerged in $150 \mathrm{~mL}$ of water at 3 different temperatures: 20,50 and $85^{\circ} \mathrm{C}$, respectively. The samples were removed at different times $(2,4,6,10,15,20,25,30,35$, 40, 50 and $60 \mathrm{~min}$ ). The final weight of the samples was recorded after removing the excess of water from the surface with absorbent paper. The rehydration ratio was calculated as the maximum amount of water absorbed $(\mathrm{g})$ per $\mathrm{g}$ of dehydrated material for each experiment at the different times as proposed by Domaz [8]. Tests were conducted in duplicate.

\section{Results and discussion}

\subsection{Air drying kinetics}

During the drying process the moisture content of the samples was monitored at different times. The coefficients of drying models and the goodness of fit for chayote samples are given in Table 1. In general, the Page model sufficiently described the drying kinetics for strips and cubes (Fig. 1 and Table 1). All samples showed a slight losss of wáter at the beginning of the process but in the case of slices this slight loss was also observed at the gap of time between 120 and $180 \mathrm{~min}$ (Fig. 1). The best model fit for slices was observed with a polinomial model (Fig. 1).

Table 1. Coefficients of convective drying models and goodness of fit for chayote samples

\begin{tabular}{ccccc}
\hline Model & Equation & Sample & Parameter & $\mathbf{R}^{2}$ \\
\hline Newton & $M_{R}=\exp (-\mathrm{kt})$ & Strips & $\mathrm{k}=0.0155$ & 0.9476 \\
& & Cubes & $\mathrm{k}=0.0129$ & 0.8257 \\
& & Slices & $\mathrm{k}=0.0083$ & 0.6167 \\
Henderson- & $M_{R}=\mathrm{a}^{*} \exp \left(-\mathrm{k}_{2} \mathrm{t}\right)$ & Strips & $\mathrm{k}_{2}=0.0153 ; \mathrm{a}=1.1810$ & 0.9315 \\
Pabis & & & & \\
& & Cubes & $\mathrm{k}_{2}=0.0129 ; \mathrm{a}=1.4783$ & 0.8237 \\
& & Slices & $\mathrm{k}_{2}=0.0097 ; \mathrm{a}=1.4264$ & 0.6128 \\
Page & $M_{R}=\left(-\mathrm{k}_{3} \mathrm{t}^{\mathrm{n}}\right)$ & Strips & $\mathrm{k}_{3}=0.0051 ; \mathrm{n}=1.2$ & 0.9521 \\
& & Cubes & $\mathrm{k}_{3}=4.2868 \times 10^{-7} ; \mathrm{n}=2.9$ & 0.9866 \\
& & Slices & $\mathrm{k}_{3}=4.2868 \times 10^{-7} ; \mathrm{n}=2.9$ & 0.9167 \\
\hline
\end{tabular}

The drying kinetics for sliced samples of chayote previously reported showed a typical first-order kinetic shape. The structure of the seed of chayote is shown in Fig. 2. In general, the seed is composed by three structures: the endocarp, the endosperm, and the cotiledons and it differentiates from other seeds in that its moisture content remains high during maturity. Moreover, the seed remains intact within the fleshy fruit [9]. In the light of the structure of the seed, it seems that the shape of the drying kinetics of the chayote slices 
determined in the present work corresponds to a first period into which water loss of flesh occurs and a second period corresponding to the subsequent drying of the seed. Akonor and Tortoe [10] worked with the drying of slices of chayote of thickness of $4 \pm 1 \mathrm{~mm}$. Eventhough they did not report neither the exact variety nor the state of maturity of the samples used in the tests a photograph included in their study suggests that the internal structure of the seed of the variety used in their study differs from the structure of the seed used in the present study. As for Huerta-Mora et al. [11], they worked with the drying of slices of chayote of thickness of $2 \mathrm{~cm}$. This fact may diminish the wáter diffusivity of the wáter in the flesh of the fruit, thus, led to a drying kinetic of first order.

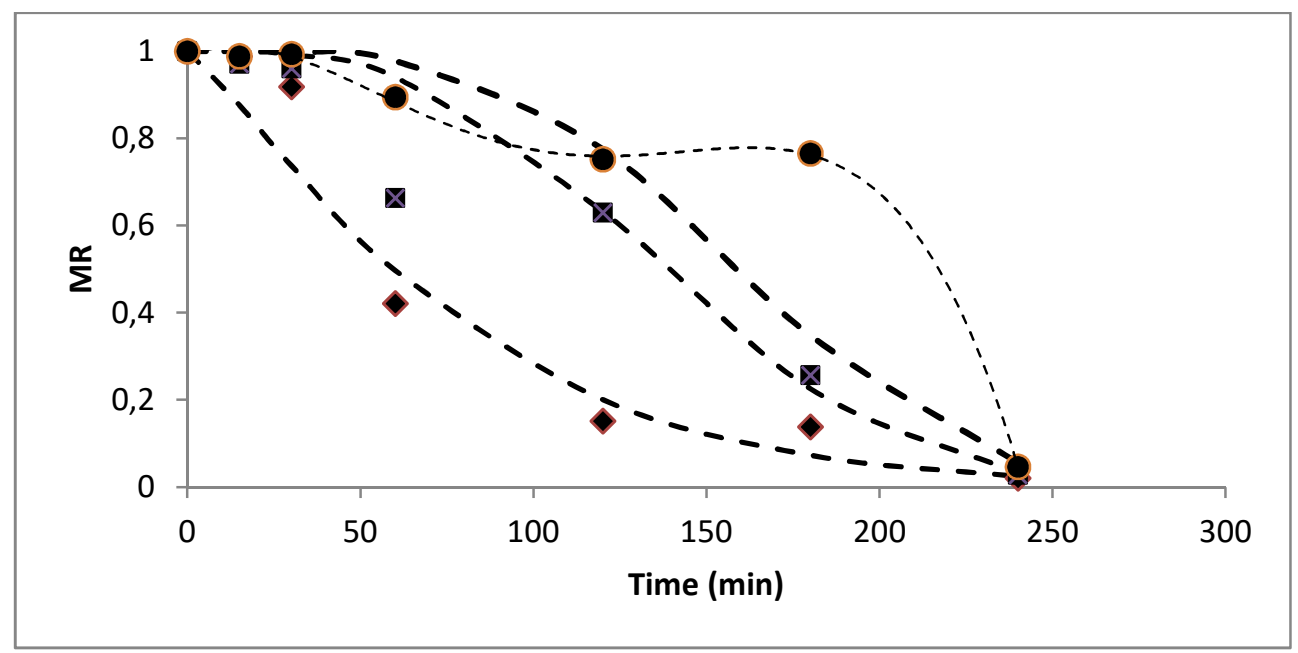

Fig. 1 Drying kinetics of chayote samples $\left(T=60^{\circ} \mathrm{C}\right)$. Circles correspond to sliced samples, squares to cubes and the diamonds to strips.

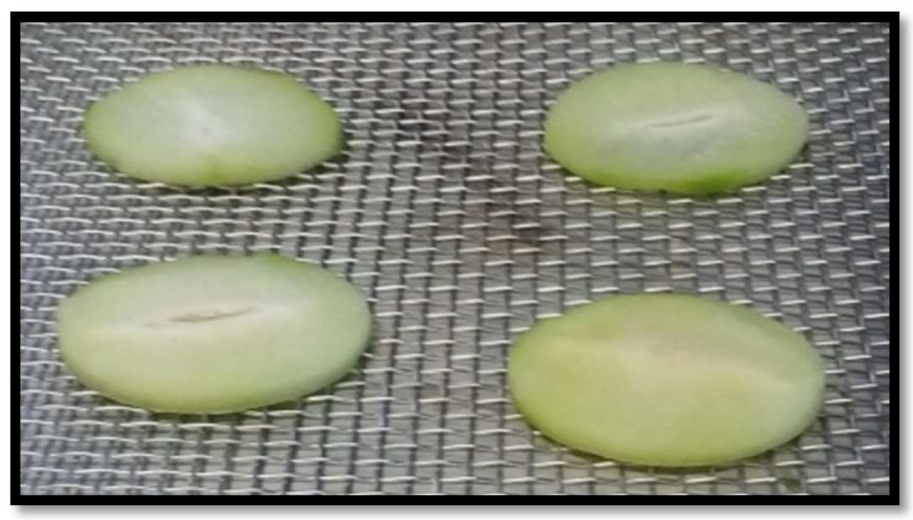

Fig. 2 Chayote slices. 
There are few reports in the literature regarding the drying kinetics of cubes and strips of chayote. The calculated values for the coefficients of the Newton model (Table 1) for cubes and strips samples are three times greater in average than those calculated by Ruíz-López [5] for slices. These may indicate that the water loss is facilitated by the shape and the smaller volume of the samples submitted to a drying process which may also be reflected in the rehydration of the samples as it will be discussed below.

\subsubsection{Color change of samples of chayote during the drying process}

The color change of the different samples of chayote was followed during the drying process. In general, results showed that in general samples after $240 \mathrm{~min}$ of drying are slightly darker, less greener and yellower than samples before drying. $\Delta \mathrm{E}$ determination revealed that the samples that registered less color change correspond to the ones cut into slices followed by cubes.

\subsection{Rehydration process of different shapes of dried chayote samples}

The rehydration process of the samples of chayote is shown in Fig. 3. In general, the degree of rehydration increased in the first minutes and diminished with time in accordance with the reported previously [11]. The time in which the degree of rehydration began to stabilize corresponds to $20 \mathrm{~min}$ for strips, $30 \mathrm{~min}$ for slices and $25 \mathrm{~min}$ for cubes. The samples that showed a higher capacity of rehydration were the ones cut into cubes in contrast with the chayote slices which showed the lesser rehydration ratio among all samples. Also, higher rehydration ratios were observed when higher water temperatures were employed as reported by Kumar et al [12] for chayote samples (Fig. 3). In order to better explain the higher water gain in cubes, we performed an image analysis with the software ImageJ(C to assess the differences of the samples' sizes before and after rehydration. We also calculated the surface area of the dehydrated samples. Tests revealed that the samples that showed the higher ratio surface area and volume corresponds to the cubes followed by the strips and slices. In fact, both, chayote strips and cubes showed a moderate deformation on its length and thickness and length after drying, respectively. However, the samples in cubes recovered its original shape more easily than strips possible due to less mechanical stress present in cubes compared to strips. Despite this fact, all samples presented good rehydration ratios (Fig. 3). Interestingly, Kumar et al [12] reported lesser rehydration ratios for chayote cubes with the same size of our samples $(L=1 \mathrm{~cm})$ compared with the ones found in the present work. According to Lewicki [13], pre-drying and drying may limit the water absorption of plant tissue and at the same time both procedures may intensify the leakage of solubles. Thus, the difference on the rehydration ratios of the samples observed by Kumar et al [12] and us may be due to the pre-drying treatment used by Kumar et al [12] which could led to the leakage of solubles of the samples. 


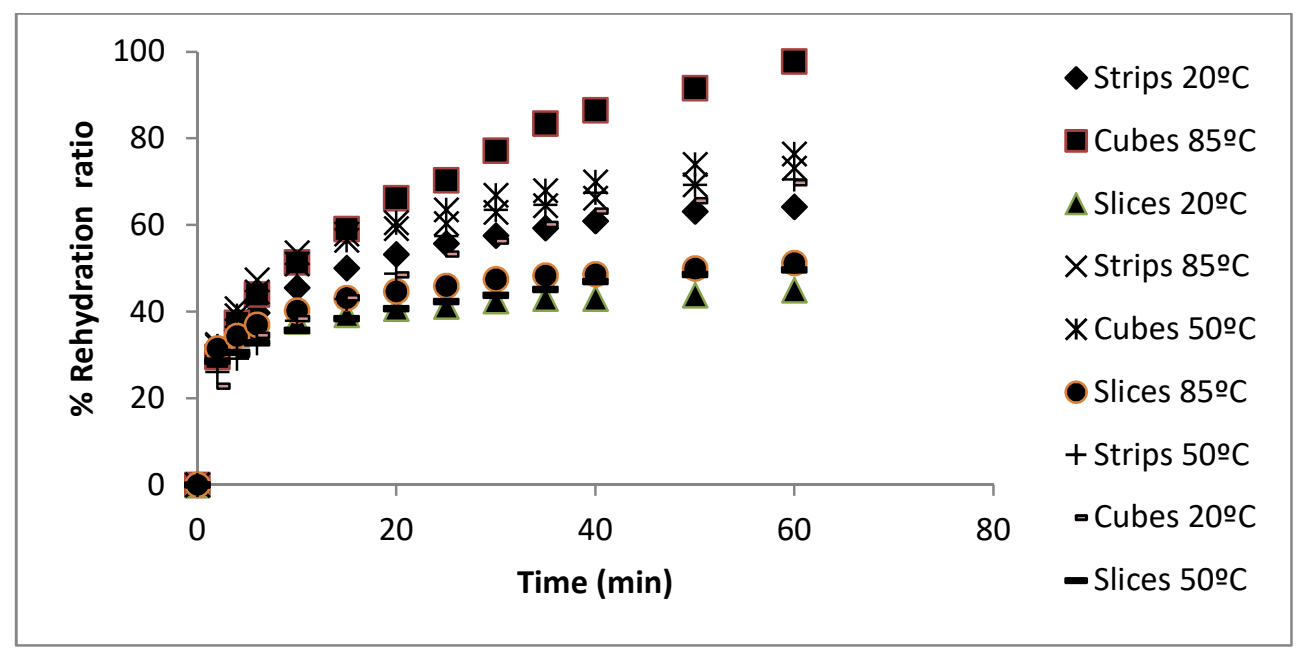

Fig. 3. Rehydration ratios at 20,50 and $85^{\circ} \mathrm{C}$ of chayote samples.

\section{Conclusions}

The moisture content of chayote samples was reduced by more than $85 \%$ through convective drying at $60^{\circ} \mathrm{C}$ showing a slight color change at this temperature. Samples in slices showed a second water loss period unlike the other shapes studied which could be attributed to the presence of the seed in these tests. As for the rehydration process, after 60 minutes at three different temperatures $\left(20,50\right.$ and $\left.85^{\circ} \mathrm{C}\right)$, the samples showed a rehydration capacity between $53-98 \%$ which confirmed that the internal structure of the samples did not suffer significant structural damage due to convective drying. Also, the rehydration capacity tend to increase as the temperature of the fluid increases as previously reported [12]. According to the results obtained, dried chayote may represent an alternative as complement of food products and, particularly, samples in cubes represent an alternative for commercial use as an additive in instant soups due to their size.

\section{References}

[1] Kader, A.; Rolle, R. The role of post-harvest management in assuring the quality and safety of horticultural produce; FAO: Rome, 2004.

[2] Alvarenga-Venutolo, S.; Abdelnour-Esquivel, A.; Villalobos-Aránbula, V. Conservación in vitro de chayote (Sechium edule). Agronomía Mesoamericana 2007, $18(1), 65-73$. 
[3] Castillo-Reyes, J.; Luna-Solano, G.; Cantú-Lozano, D. Rheological Characterization of Vegetal Pear (Sechium edule). In AIP Conference Proceedings. AIP, 2008. p. 12531255 .

[4] Pérez-Francisco, J.M.; Cerecero-Enríquez, R.; Andrade-González; Ragazzo-Sánchez, J.A.; Luna-Solano, G. Optimization of vegetal pear drying using response surface methodology. Drying Technology 2008, 26: 1401-1405.

[5] Ruiz-López, I.I.; Huerta-Mora, I. R.; Vivar-Vera, M. A.; Martínez-Sánchez, C. E.; Herman-Lara, E. Effect of osmotic dehydration on air-drying characteristics of chayote. Drying Technology 2010, 28(10), 1201-1212.

[6] Avendaño-Arrazate, C. H.; Cadena-Iñiguez, J.; Arévalo-Galarza, M.; Campos-Rojas, E.; Cisneros-Solano, V.; Aguirre-Medina, J. Las variedades del chayote mexicano, recurso ancestral con potencial de comercialización. México: Grupo Interdisciplinario de Investigación en Sechium edule en México, AC, 2010.

[7] COVECA. 2005. Perfil del chayote, Boletín de la Comisión Veracruzana de Comercialización. Mexican Journal 41-44.

[8] Doymaz, I. Influence of Blanching and Slice Tthickness on Drying Characteristics of Leek Slices. Chemical Engineering and Processing 2008, 47, 41-47.

[9] Aung, L.; Harris, C.; Jenner, J. Chemical growth regulators on postharvest sprout development of Sechium edule Swartz. Phyton (Buenos Aires) 2004, 73, 155-164.

[10] Akonor, P.; Tortoe, C. Effect of blanching and osmotic pre-treatment on drying kinetics, shrinkage and rehydration of chayote (Sechium edule) during convective drying. British Journal of Applied Science and Technology 2014, 4(8), 1215-1229.

[11] Muñoz-López, C.; Urrea-Garcia, G.; Jiménez-Fernandez, M.; Rodríguez-Jiménes, G.; Luna-Solano, G. Effect of drying methods on the physicochemical and thermal properties of Mexican plum (Spondias purpurea L.). CyTA-Journal of Food 2018, 16(1), 127-134.

[12]Kumar , A.; Islam, S.; Kumar, K.; Sarkar, S. Optimization of process parameters for osmotic dehydration of chayote cubes by response surface methodology. International Journal of Agriculture, Environment and Biotechnology 2017, 10(6), 725-737.

[13] Lewicki, P. Effect of pre-drying treatment, drying and rehydration on plant tissue properties: A review. International Journal of Food Properties 1998, 1(1), 1-22. 